\title{
New Technologies and the Demand for Medium Qualified Labour in Germany
}

\author{
Peter Jacobebbinghaus and Thomas Zwick*
}

April 27, 2001

\begin{abstract}
The literature on skill-biased technological change concentrates on highly skilled and unskilled employees. It is unclear, however, if the employment opportunities of the majority of the labour force in Germany - employees with a degree from the dual apprenticeship system - increase or not. In addition, estimation and data problems are addressed in a topical and rich data set. The paper shows that innovation expenditures and investments in information and communication technologies lead to lower medium skilled employee shares, whereas other investments lead to higher shares.
\end{abstract}

JEL codes: C24, J23, O32

Keywords: Dual apprenticeship system, qualification demand, innovation, CLAD, SCLS

${ }^{*}$ We thank Dirk Czarnitzki, Bernd Fitzenberger, Arnd Kölling, François Laisney, Johannes Ludsteck, and Ralf-Henning Peters for very useful discussions and comments. 


\section{Introduction}

Traditionally the dual apprenticeship system is the backbone of professional qualification in Germany. In 1998, according to the German federal statistical office, the highest professional qualification of about $55 \%$ of the labour force is a degree from the German dual apprenticeship system. ${ }^{1}$ This share decreased only slightly in recent years. Therefore the dual apprenticeship system is by far the most important institution to acquire a professional degree in Germany. Year by year, the German government invests considerable effort in goodwill campaigns in order to promote the willingness of firms to have apprentices, see Franz, Steiner, and Zimmermann (2000). As a consequence, the public awareness of the importance is high and almost $100 \%$ of the German firms accept a social responsibility of the firms to offer apprenticeships, see Zwick and Schröder (2001).

Germany takes pride in the qualification results of its extensive and expensive dual apprenticeship system. Three parties, the training firm, the apprentice and the government finance the mainly three year apprenticeship (see Franz and Soskice, 1995, and Harhoff and Kane, 1997). The apprenticeship comprises education in public training schools and theoretical as well as practical training within the company. The dual apprenticeship system is praised even by most German companies that do not offer apprenticeships as an efficient means to provide qualified personnel with topical and general skills. Few German enterprises indicate that they consider the skill level of their former apprentices to be inadequate, see Zwick and Schröder (2001).

Graduates of the dual apprenticeship system are well educated in an international comparison, see Acemoglu and Pischke (1999)) and have a comparable professional position to for example high school graduates in the USA (see Harhoff and Kane, 1997). Freeman and Schettkat (1999) stress that literacy and numeracy scores of medium skilled employees in Germany are higher than those of American employees with some college or an associate degree. The apprenticeship diplomas are monitored by the local chambers of commerce and work councils, have the same level for all participating apprentices regardless the training firm they come from and entail skills generally applicable in the business sector of the apprentice (see Franz and Soskice, 1995, and Zwick and Schröder, 2001). Therefore the basic knowledge necessary to acquire an apprenticeship degree in Germany can be labeled as general, well-known for everybody and marketable elsewhere, see Franz et al. (2000).

Technological change always implies the necessity to train and therefore employees need a broad background of general skills that allows them to acquire new skills easily in order to benefit from the introduction for example of new technologies, see Bartel and Sicherman (1998) or Acemoglu and Pischke (1999). Nickell and Bell (1996) write: "The very high level of education and training embodied in the vast bulk of the German labor force enables them to respond in a flexible manner to demand shifts. As a consequence, in Germany, in contrast to Britain and the United States, we do not find a large segment of the work force

\footnotetext{
${ }^{1}$ We call this group of the labour force medium skilled for convenience in the remainder.
} 
who simply cannot cope with the demands placed upon them by technological change". Medium skilled employees in Germany are therefore in a good position to benefit from the chances provided by technological change. The hypothesis this paper assesses is that medium skilled employees can benefit from the introduction of new technologies, because the medium skilled are flexible enough and have the qualificational background that is necessary to adapt to the necessary qualificational changes implied by investments in new technologies. Therefore employment opportunities of medium skilled employees improve, because innovative firms substitute unskilled employees by them.

From the empirical literature on skill-biased technological change we know that in recent years technological change favoured highly skilled employees and replaced unskilled jobs, see Acemoglu (2000). The impact of technological change on medium skilled employees is largely unknown, however, because most papers are based on crude measures of skill ${ }^{2}$ or concentrate on the share of highly qualified or unqualified employees ${ }^{3}$. Although it is undisputed that technological change is skill biased, it is therefore still unclear which qualification groups can take advantage of technological change when we differentiate between several qualification levels, or in other words, where the dividing line lies.

The results in the literature frequently depend on the measurement of innovations, see Chennels and Van Reenen (1999). Skill upgrading does not take place in information intensive industries only, but it is pervasive and affects all sectors and employment areas, see for example Maurin and Thesmar (1999) or Falk and Seim (2001). Therefore not only IT investments, but also other innovations as driving forces of changes in the enterprises should be taken into consideration in order to assess their impact on qualification demand. In order to tackle the problem of measuring new technologies and obtain a differentiated picture of the impact of new technologies on the demand for medium qualified employees in Germany, we use three different and direct indicators for innovative activities: innovation expenditures, IT investments, and research and development.

This paper is organized as follows. The next section explains the theoretical link between innovations and qualification demand. Then the data and the estimation techniques are described. Finally, we present the estimation results and some conclusions for economic policy.

\section{Innovations and qualification demand}

The impact of innovations on the medium skilled labour demand can be analyzed in the framework of factor demand models where labour demand is expressed as a function of several determinants including indicators for innovation efforts. The functional form of factor demand models can be derived from firms' profit maxi-

\footnotetext{
${ }^{2}$ Berman, Bound, and Griliches (1994), Autor, Katz, and Krueger (1998) or Askenazy (2000) concentrate on manufacturing versus non-manufacturing employee shares, Machin and Van Reenen (1998) focus on college versus non-college employment shares.

${ }^{3}$ See Machin (1996), Kaiser (1998), or Falk and Seim (2001)
} 
mizing behaviour on the basis of flexible production functions like the generalized Leontief or the translog production function (see Berndt, 1991, chapter 9, Chennels and Van Reenen, 1999, and Morrison, 1999). These may contain variable factors as well as quasi-fixed factors like capital. By Shephard's lemma, the dual cost functions allow the derivation of factor demand and cost share equations which can be used for an empirical analysis. Important determinants of the factor demand are the prices of the variable factors. In our data, we do not observe the average wages paid to the different qualification levels. ${ }^{4}$ Therefore, we have to assume that the effects of the relative wages for the different qualification groups are captured by the firm size and sector dummies implying that they are constant within one firm size-sector combination. ${ }^{5}$ We regard innovative, IT and non-IT capital as quasi-fixed factors. As we do not have information on the level of these factors, we use innovation expenditures, IT investments and non-IT investments within one year to approximate the levels. This can be justified by the fast depreciation of innovative capital. We therefore assume that the yearly investments equal the productive IT capital, because the investments in the previous year are already obsolete (see also Falk and Seim, 2001). The approximation of non-IT capital by non-IT investments implies that non-IT capital is relatively stable over time and has constant depreciation rates between firms.

A further assumption is that the labour cost shares are independent of the production level of the firm (homothetic production function). This assumption allows us to use capital intensities instead of levels. Theory suggests nonlinear impacts of quasi-fixed factors in factor demand equations. Therefore we include quadratic terms.

It is hard to measure innovations directly. Therefore, more or less indirect measures of the innovative behaviour of firms have to be used. A positive impact of the indicators for innovation activities shows that the share of medium skilled employees and innovations are complements and innovative firms therefore employ relatively more medium skilled employees than less innovative firms.

An important measure of innovation efforts is the ratio of innovation expenditures to turnover which we call innovation intensity in the following. One problem with this measure is that innovations are hard to define and the costs for innovations are accordingly hard to calculate. Therefore, we expect a substantial subjective component in this variable.

Secondly, the ratio of investments in IT on turnover (IT intensity) is included. The use of these technologies is taken as a sign of innovative behaviour, because not all firms use them extensively yet. Their penetration rate increased rapidly in Germany. In 1979, 14\% of the employees used a computer-based tool (CNC or

\footnotetext{
${ }^{4}$ The average wages can be approximated by regressing the total wage sum on the qualification shares (see Kaiser, 2000). In explorative estimations the approximated relative wages do not have an impact on qualification shares, however. One could conclude from this that the qualification groups are paid according to their marginal productivity. This result could also be caused by the inaccuracy of the auxiliary regression, however, which has a low $R^{2}$ and some inconsistencies.

${ }^{5}$ The same assumption is implied when wages are merged or approximated by regression on the basis of firm size and sector dummies.
} 
NC machine, computer, laptop etc.), while in 1999, the share was $62 \%$. The share of medium skilled employees using new technologies was $58 \%$ in 1999 , while $33 \%$ used those technologies as their main tool, see Troll (2000). Innovative firms in the service sectors are characterized by quick introduction of the latest information and communication technologies. This is mirrored in high expenditures for these technologies. The IT intensity differs between firms and sectors. In the German service sector, the intensity is on average about $2 \%$ (see Table 3 ). This intensity varies between almost $0.8 \%$ in wholesale trade and more than $3.5 \%$ in technical services and more than $4.0 \%$ in electronic data processing (see Table 4 ).

Research and development (R\&D) activities can also be interpreted as an indicator for innovations. As it is known that R\&D activities are mainly performed by highly skilled employees (see for example Pfeiffer and Falk, 1999), we correct the employment shares for the employees in R\&D departments. Since we only observe the number of R\&D employees, but not their qualification structure, we cannot correct the skill shares directly. Instead we add the share of employees in the $R \& D$ department and a dummy if $R \& D$ projects have been carried out as control variables to measure the impact of our innovation indicators corrected for R\&D activities.

Non-IT investments over turnover (non-IT intensity) is taken as a measure for the replacement of obsolete capital by new but not necessarily innovative equipment. The share of investments induced by innovations among non-IT can be expected to be substantially smaller than among IT investments. If the firm's investment budget is fixed, IT and non-IT investments might as well be substitutes.

In addition, the sector and the size of the firm are included in the list of explanatory variables. The estimation equation can therefore be written as follows:

$$
\begin{aligned}
\frac{E}{B} & =\alpha+\beta_{I N} \frac{I N}{Q}+\beta_{I N 2}\left(\frac{I N}{Q}\right)^{2}+\beta_{I T} \frac{I T}{Q}+\beta_{I T 2}\left(\frac{I T}{Q}\right)^{2}+\beta_{N I T} \frac{N I T}{Q}+\beta_{N I T 2}\left(\frac{N I T}{Q}\right)^{2} \\
& +\beta_{A F E} \frac{A F E}{B}+\beta_{F E} d_{F E}+\sum_{m=1}^{4} \beta_{F G m} d_{F G m}+\sum_{j=1}^{9} \beta_{W Z j} d_{W Z j}+\varepsilon .
\end{aligned}
$$

Hereby, $\mathrm{E}$ is the number of employees whose highest professional degree is an apprenticeship in the dual system, B is the total number of employees, IN are innovation expenditures and IT are investments in information and communication technology, NIT are non-IT investments, Q is the turnover, AFE is the number of employees in the R\&D department, $d_{F E}$ is a dummy that equals one for firms that had $R \& D$ projects in the last three years before the interview was held, $d_{F G m}$ is a dummy for firm size, $d_{W Z_{j}}$ is a dummy for the sector (see the list of sectors in the appendix), and $\varepsilon$ is a stochastic error term.

The basis of estimation are those firms that provided information on the qualification share of their employees on a 5 level scale. We define three qualification levels: unskilled employees ${ }^{6}$, medium skilled employees (having a degree from

\footnotetext{
${ }^{6}$ In the data there is no category for employees without professional degree, but there is one
} 
the dual apprenticeship system as their highest professional qualification) and highly skilled employees (employees with master/technician degree, university or polytechnic diploma).

\section{Data and Estimation Technique}

The data basis of the estimation is the Mannheim innovation panel for service firms with its 1995 and 1997 waves that are available at that moment. The two waves contain answers for the years 1994, 1995, and 1996. The Mannheim innovation panel focuses on the innovative behaviour of service firms in Germany. It is a representative sample of most commercial service sectors (therefore excluding health care, government services and non-profit sectors) and it very closely reflects the national averages, see also Falk and Seim (2001). An in-depth description of the panel can be found in Ebling et al. (1999).

In 1995, 3522 firms participated and 2337 firms in 1997. All firms with less than 5 employees are excluded, because a change in employment by one person has a too strong effect on the qualification shares in the firm. Of those 7820 observations with 5 or more employees we have to exclude 3752 because only firms that stated to have introduced an innovation during the last three years, or at least have tried to but failed, were asked about their innovation expenditures and R\&D employees and projects. After dropping observations with missing or implausible ${ }^{7}$ values we are left with 2033 observations. Table 3 shows that variable means before and after the reduction of the sample are quite similar. This indicates that we do not have a serious selection problem.

In the middle of the nineties substantial differences in the structure and behavior of firms located in East and West Germany can be expected as the transition process after the German re-unification is not finished. Structural differences can be seen in Table 3 in the appendix which shows that the share of firms in certain industries differs between East and West. We also estimated the model described below with the pooled East and West German data but a Chow test rejected the equality of coefficients indicating behavioral differences. Therefore we did separate estimations for East and West German firms.

In order to obtain the maximal number of observations, the regressions contain pooled data with observations from all three years, leaving us with 1292 cases for West Germany and 741 cases for East Germany. Descriptive statistics of the endogeneous and exogeneous variables can be found in the appendix in Tables 3 and 4.

The share of medium skilled employees can only be between zero and one and the endogeneous variable is censored. Therefore an ordinary least squares estimation is inconsistent and the coefficients are biased towards zero (that means their absolute value is too small). The bias increases with the share of censored

summary category for all employees not in the list mentioned above.

${ }^{7}$ We regard observations with an innovation intensity greater than one, with IT investments greater than total investments and with a non-IT intensity greater than 2 as implausible. 
firms (see, for example Greene, 1997, chapter 20). In the data used, $3.9 \%$ of the firms do not employ medium skilled employees and $2.1 \%$ only employ skilled employees. Therefore estimation techniques should be applied that take account of the censoring on both sides of the endogeneous variable.

We assume a model with a latent endogeneous variable $y_{i}^{*}$, that may be interpreted as the unobservable qualification demand of firm $i$ for medium skilled employees: ${ }^{8}$

$$
y_{i}^{*}=x_{i} \beta+\varepsilon_{i} .
$$

For the observable share of medium skilled employees $y_{i}$ we obtain:

$$
y_{i}=\left\{\begin{array}{lll}
0 & \text { if } & y_{i}^{*}<0 \\
y_{i}^{*} & \text { if } & 0 \leq y_{i}^{*} \leq 1 \\
1 & \text { if } & y_{i}^{*}>1
\end{array}\right.
$$

For normally distributed and heteroscedastic error terms $\varepsilon_{i} \sim N\left(0, \sigma_{i}^{2}\right)$, we obtain the heteroscedastic tobit model. Assuming that $\sigma_{i}=e^{z_{i} \gamma}$ we maximize the log likelihood function

$$
\begin{aligned}
& \hat{\beta}_{M L}=\underset{\beta, \gamma}{\operatorname{argmax}} \ln L \\
& =\underset{\beta, \gamma}{\operatorname{argmax}} \sum_{i=1}^{N}\left(1-C 0_{i}-C 1_{i}\right) \quad\left\{-\frac{1}{2}\left[\left(\ln (2 \Pi)+\ln \left(e^{z_{i} \gamma}\right)^{2}+\left(\frac{y_{i}-x_{i} \beta}{e^{z_{i} \gamma}}\right)^{2}\right]\right\}\right. \\
& +C 0_{i} \quad \ln \left[1-F\left(\frac{x_{i} \beta}{e^{z_{i} \gamma}}\right)\right] \\
& +C 1_{i} \quad \ln \left[F\left(\frac{x_{i} \beta-1}{e^{z_{i} \gamma}}\right)\right]
\end{aligned}
$$

with $C 0_{i}$ and $C 1_{i}$ indicating if the endogenous variable is censored at 0 or 1 , while $z_{i}$ are variables explaining heteroscedasticity and $\gamma$ is the corresponding coefficient vector.

Wald-, LR- and LM-tests reject the assumption of homoscedasticity. To test the normality assumption we apply an information matrix (IM) test developed by White (1982), which was adjusted for heteroscedasticity. Normality is rejected but simulation studies by Davidson and MacKinnon (1992) and Orme (1992) reveal the weak performance of the IM test which in finite samples rejects the true null hypothesis much too often even in the homoscedastic case and with few variables. As can be expected, own simulations show that this problem increases considerably in the heteroscedastic case. To check the reliability of the heteroscedastic tobit estimation that hinges on the normality assumption, we therefore apply two semiparametric methods developed by Powell $(1984,1986)$ that do not rely on this assumption: the censored least absolute deviation (CLAD) estimator

\footnotetext{
${ }^{8}$ This implies the assumption that for the decision to employ no medium skilled employees, to employ a certain share of medium skilled employees or to employ only medium skilled employees the same decision process applies. A double hurdle model explicitly explaining the decision to hire medium skilled employees in a first regression and the share of the medium skilled employees in a second step is not possible, because of the small number of censored firms and because we do not have suitable additional identifying variables.
} 
and the symmetrically censored least squares (SCLS) estimator. They come at the cost of being less accurate than the tobit estimates if the error terms are in fact normally distributed and heteroscedasticity is explained completely by the scedastic equation $\sigma_{i}=e^{z_{i} \gamma}$.

The CLAD estimator models the conditional median of $y_{i} \mid x_{i}{ }^{9}$ instead of its expectation. Therefore, comparing CLAD and Tobit coefficients one implicitly assumes that the distribution of $y_{i} \mid x_{i}$ is symmetric. Being a quantile regression, CLAD minimizes the sum of the absolute deviations $\left|\hat{\varepsilon}_{i}\right|$. The minimizing problem with two-sided censoring at zero and one can be written as:

$$
\hat{\beta}_{C L A D}=\underset{\beta}{\operatorname{argmax}} \sum_{i=1}^{N}\left|y_{i}-\max \left\{0, \min \left\{1, x_{i} \beta\right\}\right\}\right| .
$$

It is not easy to directly optimize the objective function, because it is not differentiable. Therefore we use the iterative procedure proposed by Buchinsky (1994). ${ }^{10}$

Powell (1984) shows that $\hat{\beta}_{C L A D}$ also is consistent and asymptotical normally distributed if we have a non-normally distributed and heteroscedastic error term. The standard errors in Tables 1 and 2 are obtained by bootstrapping.

The SCLS estimator is based on the OLS estimator that also is consistent under heteroscedasticity. It needs symmetric error terms, however. Assume that the true value of $\beta$ is known. For observations $\left\{i \mid 0 \leq x_{i} \beta \leq 1\right\}$ we obtain the following deviations:

$$
\tilde{\varepsilon}_{i}=y_{i}-x_{i} \beta,
$$

for the case of censoring at zero and one, we get:

$$
-x_{i} \beta \leq \tilde{\varepsilon}_{i} \leq 1-x_{i} \beta .
$$

Due to this censoring the variable $\tilde{\varepsilon}_{i}$ is usually correlated with $x_{i}$. If $\varepsilon_{i}$ is symmetrically distributed, we obtain consistent OLS estimators by trimming such that $\widetilde{\varepsilon}_{i} \mid x_{i}$ is also symmetric around zero and we then obtain $E\left(\widetilde{\varepsilon}_{i} \mid x_{i}\right)=0$. The following condition must hold:

$$
\max \left\{-x_{i} \beta,-1+x_{i} \beta\right\} \leq \tilde{\varepsilon}_{i} \leq \min \left\{x_{i} \beta, 1-x_{i} \beta\right\} .
$$

This can be obtained by transforming $y_{i}$ as follows:

$$
\tilde{y}_{i}=\min \left\{-1+2 x_{i} \beta, \max \left\{y_{i}, 2 x_{i} \beta\right\}\right\} .
$$

\footnotetext{
${ }^{9}$ Other quantiles can be modeled depending on the number of censored values.

${ }^{10}$ The implementation of the iterative calculation is straightforward if the computer estimation package allows for median regressions. In iteration $t$ the procedure uses a median regression for the observations that have an estimated value in $t-1$ between zero and one. The procedure is iterated until the coefficients do not change any more which means that the estimated sample is stable (compare Jonston and DiNardo, 1997, p. 445). Fitzenberger (1994) shows that the iterative procedure is under certain conditions less likely to converge than alternative algorithms and that convergence does not even guarantee a local maximum. He suggests other optimization methods and compares their performance in simulation studies (see Fitzenberger, 1997, and Fitzenberger and Winker, 1999). In our case with few censored observations the iterative procedure can be expected to converge to the maximum, however.
} 
Figure 1 demonstrates the trimming of $y_{i}$ and $\tilde{\varepsilon}_{i} \mid x_{i}$, respectively, which is symmetrically distributed around $x_{i} \beta$.

Figure 1: Transformation of the endogeneous variable in the SCLS estimation

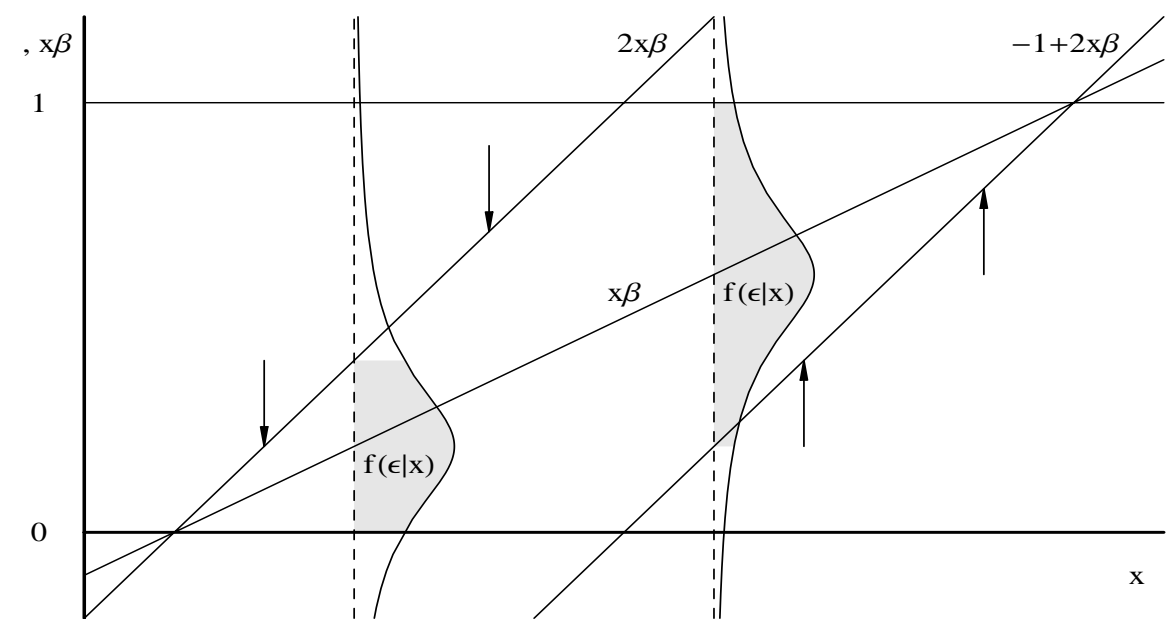

The SCLS estimator can be calculated iteratively by a series of OLS estimations (compare Jonston and DiNardo, 1997, p. 443). ${ }^{11}$ Powell (1986) shows that the SCLS estimator is consistent and asymptotical normally distributed if $\varepsilon_{i}$ is symmetrically distributed. The standard deviations in Tables 1 and 2 are calculated by bootstrapping. They hardly differ from the asymptotic values given by the formula in Powell (1986, p. 1444).

The structure of the data would allow for the use of a panel estimator in order to control for unobservable heterogeneity (see also Chennels and Van Reenen, 1999). To avoid the problem of heteroscedasticity, Honoré's fixed effects tobit estimator seems to be a promising choice. One disadvantage is that only those firms that answered in both waves could be integrated in the estimation. This leads to a further dramatic reduction in the number of observations and a potential selectivity problem, however. An additional problem is that the indicators for innovative behaviour of the firms are ratios of two separate variables which may further increase noise and the impact of measurement errors. Therefore we do not include a panel regression and leave this issue for further investigation when more waves of the panel are available.

Many firms in our data set report lack of suitably qualified personnel as a main obstacle to innovation. This points to potential endogeneity of our innovation intensities. We can not control for this as we do not have good instruments correlated with the intensities but not with the medium skilled share.

We apply the three cross section regression methods described above for West and East Germany separately. The heteroskedastic Tobit is efficient if its restrictive assumptions normality and fully explained heteroscedasticity are correct and inconsistent otherwise. SCLS is consistent under heteroscedasticity but requires

\footnotetext{
${ }^{11}$ The estimation in iteration $t$ comprises the observations $\left\{i \mid 0 \leq x_{i} \hat{\beta}_{O L S}^{t-1} \leq 1\right\}$, where $\tilde{y}_{i}^{t}$ is calculated by $\hat{\beta}_{O L S}^{t-1}$. If we have $\hat{\beta}_{O L S}^{t} \approx \hat{\beta}_{O L S}^{t-1}$, this is the result of the SCLS estimation.
} 
symmetric errors. CLAD is consistent under the most general conditions and robust to outliers, but it models the conditional median instead of the expectation of the medium skilled share. Therefore all of these methods have their advantages and drawbacks. Their common application serves as a robustness check for our results.

\section{Estimation Results}

Tables 1 and 2 present the results of the CLAD, SCLS and heteroscedastic tobit estimations for West and East Germany. First of all the results are robust regarding the choice of the estimation method. In the case of contradictory results, we would have had the problem that there is no ranking regarding the reliability of the estimators as they depend on different assumptions one might believe or not. Secondly, we find differences between West and East Germany. These are, however, only quantitative as all signs of significant coefficients point in the same direction.

According to other findings in the literature, see Pfeiffer and Falk (1999), the share of employees in the R\&D departments and the dummy indicating if R\&D projects have been carried out in the enterprise both have a negative impact on the share of medium skilled employees. A $\chi^{2}$-test indicates common significance at the $5 \%$ level. The share of employees in the R\&D departments is also an important factor in the scedastic equation of the tobit model. One explanation is that firms with a large $R \& D$ department tend to report more carefully than others.

Firm size also has the expected negative impact on the share of medium skilled employees (see also Zwick and Schröder, 2001). The larger the firm the lower the share of the endogeneous variable. Only in the regression for East Germany the reference category with 5 to 9 employees does not fit into this ranking. Firm size has a strong impact in the scedastic equation. Small firms have larger error variances. This is in part due to the discrete character of this variable. The lower the number of employees, the larger is the range between possible skill shares.

The reference sector is social and personal services. In West Germany only retail trade and banks and insurances, in East Germany also wholesale trade, transport and real estate and renting have higher medium skilled employee shares. The information intensive sectors electronical data processing and technical services belong to the sectors with lower medium skilled employee shares. In the USA it is analogously observed that sectors with high information intensity have higher shares of highly skilled employees who replace unskilled or skilled employees (compare Appelbaum and Albin, 1990, p. 44, Berman et al., 1994, or Askenazy, 2000). Regarding the scedastic equation, $\chi^{2}$-tests indicate common significance of all sector dummies at the $5 \%$ level in the regression for WestGermany and at the $1 \%$ level in the regression for East-Germany.

The impact of the indicators of innovative activity is more pronounced in West than in East Germany. As all indicators are also included as squares, we 
Table 1: Estimation of the medium skilled employees share, West Germany

\begin{tabular}{|c|c|c|c|c|}
\hline \multirow[t]{2}{*}{ Independent variables } & \multirow[t]{2}{*}{ CLAD } & \multirow[t]{2}{*}{ SCLS } & \multicolumn{2}{|c|}{ Tobit } \\
\hline & & & $\begin{array}{l}\text { regression } \\
\text { equation }\end{array}$ & $\begin{array}{l}\text { scedastic } \\
\text { equation }\end{array}$ \\
\hline Innovation intensity & $\begin{array}{c}-0.598 * \\
(0.246)\end{array}$ & $\begin{array}{l}{ }^{-0.679}{ }^{* *} \\
(0.189)\end{array}$ & $\begin{array}{l}-0.808^{* *} \\
(0.153)^{*}\end{array}$ & \\
\hline Innovation intensity squared & $0.766 * *$ & $0.829 * *$ & $0.914 * *$ & \\
\hline IT intensity & $\begin{array}{l}(0.276) \\
-1968 *\end{array}$ & $\begin{array}{c}(0.226) \\
-1268\end{array}$ & $\begin{array}{l}(0.168) \\
-1.379 * *\end{array}$ & \\
\hline II Hectistoy & $(0.844)$ & $(0.749)$ & $(0.517)$ & \\
\hline IT intensity squared & $\begin{array}{l}7.886 \\
(6613\end{array}$ & 4.642 & $6.074 *$ & \\
\hline Non-IT intensity & $(0.670$ * & $(0.455$ * & $\left.\begin{array}{l}(2.866) \\
0.423 \\
0.124\end{array}\right) * *$ & \\
\hline Non-IT intensity squared & $\begin{array}{c}-0.344 \\
(0.360)\end{array}$ & $\begin{array}{l}-0.264 \\
(0.285)\end{array}$ & $\begin{array}{l}-0.246 * \\
(0.120)\end{array}$ & \\
\hline Share employees in $R \& D$ department & $\begin{array}{c}-0.005 \\
(0.086)\end{array}$ & $\begin{array}{c}-0.092 \\
(0.060)\end{array}$ & $\begin{array}{l}-0.123^{*} \\
(0.051)\end{array}$ & $\begin{array}{l}-1.190 * * \\
(0.221)\end{array}$ \\
\hline $\mathrm{R} \& \mathrm{D}$ project has been carried out & $\begin{array}{l}-0.023 \\
(0.031)\end{array}$ & $\begin{array}{l}-0.014 \\
(0.020)\end{array}$ & $\begin{array}{l}-0.004 \\
(0.017)\end{array}$ & \\
\hline Firm size (reference: 5-9 employees) & & & & \\
\hline Firm with $10-49$ employees & $\begin{array}{c}-0.028 \\
(0.048)\end{array}$ & $\begin{array}{c}-0.051 \\
(0.029)\end{array}$ & $\begin{array}{l}-0.055 \\
(0.029)\end{array}$ & $\begin{array}{c}-0.167 * \\
(0.081)\end{array}$ \\
\hline Firm with 50-249 employees & $\begin{array}{c}-0.024 \\
(0.048)\end{array}$ & $\begin{array}{l}-0.062 \\
(0.032)\end{array}$ & $\begin{array}{l}-0.059 * \\
(0.029)\end{array}$ & $\begin{array}{l}-0.331 \\
(0.082)\end{array}$ \\
\hline Firm with more than 250 employees & $\begin{array}{c}-0.032 \\
(0.051)\end{array}$ & $\begin{array}{c}-0.059 \\
(0.032)\end{array}$ & $(0.031)^{*}$ & $\begin{array}{l}-0.355 * * \\
(0.085)\end{array}$ \\
\hline $\begin{array}{l}\text { Sector } \\
\text { (Reference: social and personal services) }\end{array}$ & & & & \\
\hline Wholesale trade & $\begin{array}{l}0.166 * \\
(0.070)\end{array}$ & $\begin{array}{c}0.090 \\
(0.047)\end{array}$ & $\begin{array}{l}0.068 \\
(0.042)\end{array}$ & $\begin{array}{c}-0.066 \\
(0.113)\end{array}$ \\
\hline Retail trade & $\begin{array}{l}0.301 * * \\
(0.067)\end{array}$ & $\begin{array}{l}0.200 \\
(0.045)\end{array}$ & $\begin{array}{l}0.182 \\
(0.042)\end{array}$ & $\begin{array}{c}-0.138 \\
(0.116)\end{array}$ \\
\hline Transport & $\begin{array}{l}0.126 \\
(0.082)\end{array}$ & $\begin{array}{l}0.058 \\
(0.049)\end{array}$ & $\begin{array}{c}0.054 \\
(0.042)\end{array}$ & $\begin{array}{c}0.104 \\
(0.114)\end{array}$ \\
\hline Banks and insurance & $\begin{array}{l}0.291 \\
(0.069)\end{array}$ & $\begin{array}{l}0.170 \\
(0.047)\end{array}$ & $\begin{array}{l}0.151)^{* *} \\
(0.041)\end{array}$ & $\begin{array}{c}-0.092 \\
(0.110)\end{array}$ \\
\hline Real estate and renting & $\begin{array}{c}0.144 \\
(0.083)\end{array}$ & $\begin{array}{c}0.090 \\
(0.057)\end{array}$ & $\begin{array}{c}0.073 \\
(0.048)\end{array}$ & $\begin{array}{c}-0.190 \\
(0.144)\end{array}$ \\
\hline Electronic data processing & $\begin{array}{c}-0.008 \\
(0.079)\end{array}$ & $\begin{array}{c}-0.069 \\
(0.052)\end{array}$ & $\begin{array}{c}-0.061 \\
(0.045)\end{array}$ & $\begin{array}{c}0.056 \\
(0.119)\end{array}$ \\
\hline Technical services & $\begin{array}{c}0.035 \\
(0.068)\end{array}$ & $\begin{array}{c}-0.043 \\
(0.045)\end{array}$ & $\begin{array}{c}-0.026 \\
(0.044)\end{array}$ & $\begin{array}{c}-0.136 \\
(0.129)\end{array}$ \\
\hline Business services & $\begin{array}{c}0.033 \\
(0.068)\end{array}$ & $\begin{array}{c}-0.020 \\
(0.046)\end{array}$ & $\begin{array}{c}-0.035 \\
(0.041)\end{array}$ & $\begin{array}{l}0.019 \\
(0.109)\end{array}$ \\
\hline Constant & $\begin{array}{l}0.352 \\
(0.081)\end{array}$ & $\begin{array}{l}0.463{ }^{* *} \\
(0.051)\end{array}$ & $\begin{array}{l}0.484 \\
(0.047)\end{array}$ & 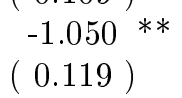 \\
\hline Number of observations & 1292 & 1292 & & \\
\hline
\end{tabular}

Note: Standard deviations are shown in brackets. Significance levels of the variables are: $*<0.05$ and $* *<0.01$. 
Table 2: Estimation of the medium skilled employees share, East Germany

\begin{tabular}{|c|c|c|c|c|}
\hline \multirow[t]{2}{*}{ Independent variables } & \multirow[t]{2}{*}{ CLAD } & \multirow[t]{2}{*}{ SCLS } & \multicolumn{2}{|c|}{ Tobit } \\
\hline & & & $\begin{array}{l}\text { regression } \\
\text { equation }\end{array}$ & $\begin{array}{l}\text { scedastic } \\
\text { equation }\end{array}$ \\
\hline Innovation intensity & 0.022 & -0.151 & -0.248 & \\
\hline & $(0.250)$ & $(0.404)$ & & \\
\hline Innovation intensity squared & 0.119 & 0.382 & 0.323 & \\
\hline & $(0.270)$ & $(0.740)$ & $(0.186)$ & \\
\hline IT intensity & -0.880 & -1.236 & $-1.656 * *$ & \\
\hline & $(0.856)$ & $(0.980)$ & $(0.535)$ & \\
\hline IT intensity squared & 2.187 & 3.300 & $5.250 *$ & \\
\hline & $(3.270)$ & $(3.342)$ & ( 2.178$)$ & \\
\hline Non-IT intensity & 0.102 & 0.053 & 0.042 & \\
\hline & $(0.177)$ & $(0.185)$ & $(0.119)$ & \\
\hline Non-IT intensity squared & -0.104 & -0.041 & -0.026 & \\
\hline & $(0.145)$ & $(0.130)$ & $(0.084)$ & \\
\hline Share employees in $\mathrm{R} \& \mathrm{D}$ department & $\begin{array}{c}-0.168 \\
(0.086)\end{array}$ & $\begin{array}{c}-0.216 \\
(0.455)\end{array}$ & $\begin{array}{c}-0.070 \\
(0.067)\end{array}$ & $\begin{array}{l}-0.847 \text { ** } \\
(0.220)\end{array}$ \\
\hline $\mathrm{R} \& \mathrm{D}$ project has been carried out & -0.039 & -0.041 & -0.049 & \\
\hline Firm size (reference: 5-9 employees) & $(0.035)$ & $(0.055)$ & $(0.027)$ & \\
\hline Firm with 10-49 employees & 0.034 & 0.057 & 0.031 & $-0.397 * *$ \\
\hline & $(0.041)$ & $(0.055)$ & $(0.034)$ & $(0.100)$ \\
\hline Firm with 50-249 employees & 0.035 & 0.012 & 0.026 & $-0.367^{* *}$ \\
\hline & $(0.045)$ & $(0.057)$ & $(0.037)$ & $(0.108)$ \\
\hline Firm with more than 250 employees & $\begin{array}{c}-0.028 \\
(0.060)\end{array}$ & $\begin{array}{c}-0.016 \\
(0.062)\end{array}$ & $\begin{array}{c}-0.015 \\
(0.043)\end{array}$ & $\begin{array}{l}-0.362 \\
(0.119)\end{array}$ \\
\hline $\begin{array}{l}\text { Sector } \\
\text { (Reference: social and personal services) }\end{array}$ & & & & \\
\hline Wholesale trade & $\begin{array}{l}0.4488^{* *} \\
(0.073)^{*}\end{array}$ & $\begin{array}{l}0.3900^{* *} \\
(0.097)^{*}\end{array}$ & $\begin{array}{l}0.2633^{* *} \\
(0.060)^{*}\end{array}$ & $\begin{array}{c}-0.289 \\
(0.150)\end{array}$ \\
\hline Retail trade & $\begin{array}{l}0.4822^{* *} \\
(0.074)\end{array}$ & $\begin{array}{l}0.395 \\
(0.090)\end{array}$ & $\left(\begin{array}{l}0.242 \\
(0.058)\end{array}\right.$ & $\begin{array}{c}-0.263 \\
(0.141)\end{array}$ \\
\hline Transport & $\begin{array}{l}0.554 * * \\
(0.077)\end{array}$ & $\left(0.4400^{* *}\right.$ & $\left.\begin{array}{l}0.309 \\
(0.065\end{array}\right)^{* *}$ & $\begin{array}{l}0.028 \\
(0.143)\end{array}$ \\
\hline Banks and insurance & $\left(\begin{array}{l}0.407^{* *} \\
(0.088)^{*}\end{array}\right.$ & $\left(\begin{array}{l}0.329)^{* *} \\
0.096)^{*}\end{array}\right.$ & $\begin{array}{l}0.2066^{* *} \\
(0.061)^{*}\end{array}$ & $(0.146)$ \\
\hline Real estate and renting & $\begin{array}{l}0.420 \\
(0.090)\end{array}$ & $\begin{array}{l}0.3455^{* *} \\
(0.088)^{*}\end{array}$ & $\begin{array}{l}0.2288^{* *} \\
(0.066)^{*}\end{array}$ & $\begin{array}{l}-0.343^{*} \\
(0.165)\end{array}$ \\
\hline Electronic data processing & $\begin{array}{l}0.094 \\
(0.076)\end{array}$ & $\begin{array}{c}0.077 \\
(0.117)\end{array}$ & $\begin{array}{l}-0.004 \\
(0.061)\end{array}$ & $\begin{array}{l}-0.4822^{* *} \\
(0.172)^{*}\end{array}$ \\
\hline Technical services & $\begin{array}{l}0.1444^{*} \\
(0.066)\end{array}$ & $\begin{array}{c}0.113 \\
(0.097)\end{array}$ & $\begin{array}{c}0.001 \\
(0.054)\end{array}$ & $\begin{array}{l}-0.543^{* *} \\
(0.129)\end{array}$ \\
\hline Business services & $\begin{array}{l}0.166 * \\
(0.081)\end{array}$ & $\begin{array}{c}0.172 \\
(0.101)\end{array}$ & $\begin{array}{c}0.061 \\
(0.059)\end{array}$ & $\begin{array}{c}-0.071 \\
(0.139)\end{array}$ \\
\hline Constant & $\begin{array}{c}0.143 \\
(0.083)\end{array}$ & $\begin{array}{c}0.192 \\
(0.108)\end{array}$ & $\begin{array}{l}0.326 \\
(0.063)\end{array}$ & $\begin{array}{l}-0.7377^{* *} \\
(0.147)\end{array}$ \\
\hline Number of observations & 741 & 741 & & \\
\hline
\end{tabular}

Note: Standard deviations are shown in brackets. Significance levels of the variables are: $*<0.05$ and $* *<0.01$. 
plotted the nonlinear effects in Figure 3 in the appendix. In Figure 4 confidence intervals for all estimators are added. We plotted the effects for values smaller than 0.5 because only a few firms have higher values. The distribution of the innovation indicators is plotted in Figure 2.

In West German firms the impact of innovation intensity on the medium skilled share is negative. Also IT intensity has a significantly negative impact. Since the IT intensities are rarely above $20 \%$, the directions of the effects are unambiguous for the relevant values and cannot be interpreted for larger values which is also reflected by the confidence intervals. Non-IT intensity has a significant positive impact. For East German firms the estimation methods render the same signs for the coefficients of innovation intensity, IT intensity and non-IT intensity. Their impact is insignificant, however, see Figure 4.

Therefore our hypothesis is rejected. Medium skilled employees in Germany are no complements for new technologies and have a lower share in information intensive and innovative firms although they have a relatively high qualification level. Therefore the dividing line between the qualification levels that benefit from the introduction of new technologies in Germany and those that loose is above the employees with a degree from the dual apprenticeship system.

\section{Conclusions}

This paper shows that the share of employees with a degree from the German dual apprenticeship system in the service sector is lower in firms with higher innovation expenditures and in firms with high IT investments. Non-IT investments that are interpreted as proxies for replacement efforts have a positive impact, however. We therefore conclude that innovative German firms do not only replace low skilled employees but also employees with a degree from the dual apprenticeship system by higher skilled employees.

IT investment is crucial for the growth of the economy, see Jorgenson and Stiroh (1999), and the main employment potentials can be found in information intensive and innovative firms like business services ${ }^{12}$ (see for example Kaiser, 1998, or Zwick and Schröder, 2001). Therefore the negative impact of innovations and IT investment on skilled labour demand is a worrying sign for decreased job opportunities for more than half of the German labour force in the most promising sectors of the economy.

It is not clear, why German IT intensive and innovative firms demand relatively few medium skilled employees. One reason might be that these firms offer jobs that traditionally require high skilled employees and investments in new technologies did not decrease qualification demand. Another reason may be that investments in new technologies require qualifications that are not met by medium skilled employees. This question is not resolved yet. First evidence for the second hypothesis is given in representative interviews in the German service

\footnotetext{
${ }^{12}$ These are: Renting, electronic data processing and data bases, research and development and other business services.
} 
sector $^{13}$. Especially the information intensive and innovative business service enterprises indicated that one of the main reasons for the low share of medium skilled employees are gaps in qualifications. Typical qualificational bottlenecks identified were computer skills, qualifications around new information technologies and foreign languages. Most frequently these qualificational gaps were stated in commercial professions that have a high employment share in services.

It therefore seems to be a viable option to increase medium skill employment shares in information intensive enterprises by bridging the skill gaps identified by the enterprises. The German state also has a direct impact on the qualification of the apprentices, because it sets the minimum requirements that have to be fulfilled in order to pass the exams. In addition it is responsible for the financial and personal endowment of the public professional schools that are an essential part of the dual apprenticeship system. A more adequate qualification of the medium skilled employees therefore can increase the attractiveness of the German dual apprenticeship system and the job opportunities of the majority of employees in a crucial employment sector.

\footnotetext{
${ }^{13}$ In April 2000, more than 1500 enterprises in this sector have been extensively asked about their perception of the dual apprenticeship system, see Zwick and Schröder (2001) and Zwick (2001).
} 


\section{References}

Acemoglu, D. (2000). Technical Change, Inequality, and the Labor Market (Discussion Paper 7800). NBER, Cambridge MA.

Acemoglu, D., and Pischke, J.-S. (1999). Beyond Becker: Training in Imperfect Labor Markets. Economic Journal, 109, 112-142.

Appelbaum, E., and Albin, P. (1990). Shifts in Employment, Occupational Structure, and Educational Attainment. In T. Noyelle (Ed.), Skills, Wages, and Productivity in the Service Sector (pp. 31-66). Westview Press: Boulder.

Askenazy, P. (2000). Organisational Innovations, Computerisation and Employment. In M. Vivarelli and M. Pianta (Eds.), Employment Impact of Innovation-Evidence and Policy. Routledge.

Autor, D., Katz, L., and Krueger, A. (1998). Computing Inequality: Have Computers Changed the Labor Market. Quarterly Journal of Economics, 113, 1169-1213.

Bartel, A., and Sicherman, N. (1998). Technological Change and the Skill Acquisition of Young Workers. Journal of Labor Economics, 16, 718-763.

Berman, E., Bound, J., and Griliches, Z. (1994). Changes in the Demand for Skilled Labor within U.S. Manufacturing: Evidence from the Annual Survey of Manufacturers. Quarterly Journal of Economics, 109, 367-397.

Berndt, E. R. (1991). The Practice of Econometrics: Classic and Contemporary. Sydney: Addison-Wesley.

Buchinsky, M. (1994). Changes in the U.S. Wage Structure 1963-1987: Application of Quantile Regression. Econometrica, 62, 405-458.

Chennels, L., and Van Reenen, J. (1999). Technical Change and the Structure of Employment and Wages: A Survey of the Micro-Economic Evidence (Discussion Paper 99/27). Institute for Fiscal Studies, London.

Davidson, R., and MacKinnon, J. G. (1992). A New Form Of The Information Matrix Test. Econometrica, 60, 145-157.

Ebling, G., Hipp, C., Janz, N., Licht, G., and Niggemann, H. (1999). Innovationsaktivitäten im Dienstleistungssektor-Ergebnisse der Innovationserhebung 1997. In N. Janz and G. Licht (Eds.), Innovationsaktivitäten in der deutschen Wirtschaft (pp. 99-222). Baden-Baden: Nomos.

Falk, M., and Seim, K. (2001). The Impact of Information Technology on Highskilled Labor in Services: Evidence from Firm-Level Panel Data. Economics of Innovation and New Technology, forthcoming. 
Fitzenberger, B. (1994). A Note on Estimating Censored Quantile Regressions (Discussion Paper 14). Konstanz University.

Fitzenberger, B. (1997). A Guide to Censored Quantile Regressions. In G. Maddala and C. Rao (Eds.), Handbook of Statistics, Vol. 15: Robust Inference (pp. 405-437). Amsterdam: North-Holland.

Fitzenberger, B., and Winker, P. (1999). Improving the Computation of Censored Quantile Regressions (Discussion Paper 568-99). Mannheim University.

Franz, W., and Soskice, D. (1995). The German Apprenticeship System. In F. Butler, W. Franz, R. Schettkat, and D. Soskice (Eds.), Institutional Framework and Labor Market Performance (pp. 208-234). Routledge, London and New York.

Franz, W., Steiner, V., and Zimmermann, V. (2000). Die betriebliche Ausbildungsbereitschaft im technologischen und demographischen Wandel. BadenBaden: Nomos.

Freeman, R., and Schettkat, R. (1999). The Role of Wage and Skill Differences in US-German Employment Differences. Jahrbücher für Nationalökonomie und Statistik, 219, 49-66.

Greene, W. H. (1997). Econometric Analysis. London: Prentice-Hall.

Harhoff, D., and Kane, T. (1997). Is the German Apprenticeship system a panacea for the U.S. labor market? Journal of Population Economics, 10, $171-196$.

Jonston, J., and DiNardo, J. E. (1997). Econometric Methods. New York: MacGraw-Hill.

Jorgenson, D., and Stiroh, K. (1999). Information Technology and Growth. American Economic Review, 89, 109-115.

Kaiser, U. (1998). The Impact of New Technologies on the Demand for Heterogenous Labour: Evidence from the German Business-Related Services Sector (Discussion Paper 98-26). ZEW (Centre for European Economic Research Mannheim).

Kaiser, U. (2000). A Note on the Calculation of Firm-specific and Skill-specific Labour Costs from Firm-level Data. Zeitschrift für Wirtschafts- und Sozialwissenschaften, 220, 541-551.

Machin, S. (1996). Changes in the relative demand for skills. In A. Booth and D. Snower (Eds.), Acquiring Skills (p. 129-147). Cambridge University Press. 
Machin, S., and Van Reenen, J. (1998). Technology and changes in Skill Structure: Evidence from seven OECD Countries. Quarterly Journal of Economics, 113, 1215-1243.

Maurin, E., and Thesmar, D. (1999). Changes in the Demand for Skilled Labor: Technological vs. Organizational Factors (Mimeo). Paris: INSEE-CREST.

Morrison, C. J. (1999). Cost Structure And The Measurement Of Economic Performance. Boston Dordrecht London: Kluwer Academic Publishers.

Nickell, S., and Bell, B. (1996). Changes in the Distribution of Wages and Unemployment in OECD Countries. American Economic Review, 86, 302308.

Orme, C. (1992). The Sampling Performance Of The Information Matrix Test. In L. Godfrey (Ed.), The implementation and constructive use of misspecification tests in econometrics. Manchester: Manchester University Press.

Pfeiffer, F., and Falk, M. (1999). Der Faktor Humankapital in der Volkswirtschaft-Berufliche Spezialisierung und technologische Leistungsfähigkeit. Baden-Baden: Nomos.

Powell, J. L. (1984). Least Absolute Deviations Estimation for the Censored Regression Model. Journal of Econometrics, 25, 303-325.

Powell, J. L. (1986). Symmetrically Trimmed Least Squares Estimation for Tobit Models. Econometrica, 54, 1435-1460.

Troll, L. (2000). Die Arbeitsmittellandschaft in Deutschland im Jahre 1999. In W. Dostal, R. Jansen, and K. Parmentier (Eds.), Wandel der Erwerbsarbeit: Arbeitssituation, Informatisierung, berufliche Mobilität und Weiterbildung (pp. 125-150). Nürnberg: IAB.

White, H. (1982). Maximum Likelihood Estimation Of Misspecified Models. Econometrica, 50, 1-25.

Zwick, T. (2001). Beschäftigungsmöglichkeiten von Fachkräften mit Dualer Ausbildung in informationsintensiven Dienstleistungsunternehmen. Mitteilungen aus der Arbeitsmarkt- und Berufsforschung, 34, forthcoming.

Zwick, T., and Schröder, H. (2001). Wie aktuell ist die Berufsbildung im Dienstleistungssektor? Baden-Baden: Nomos. 


\section{A Appendix}

Figure 2: Distribution of innovation, IT and non-IT intensities

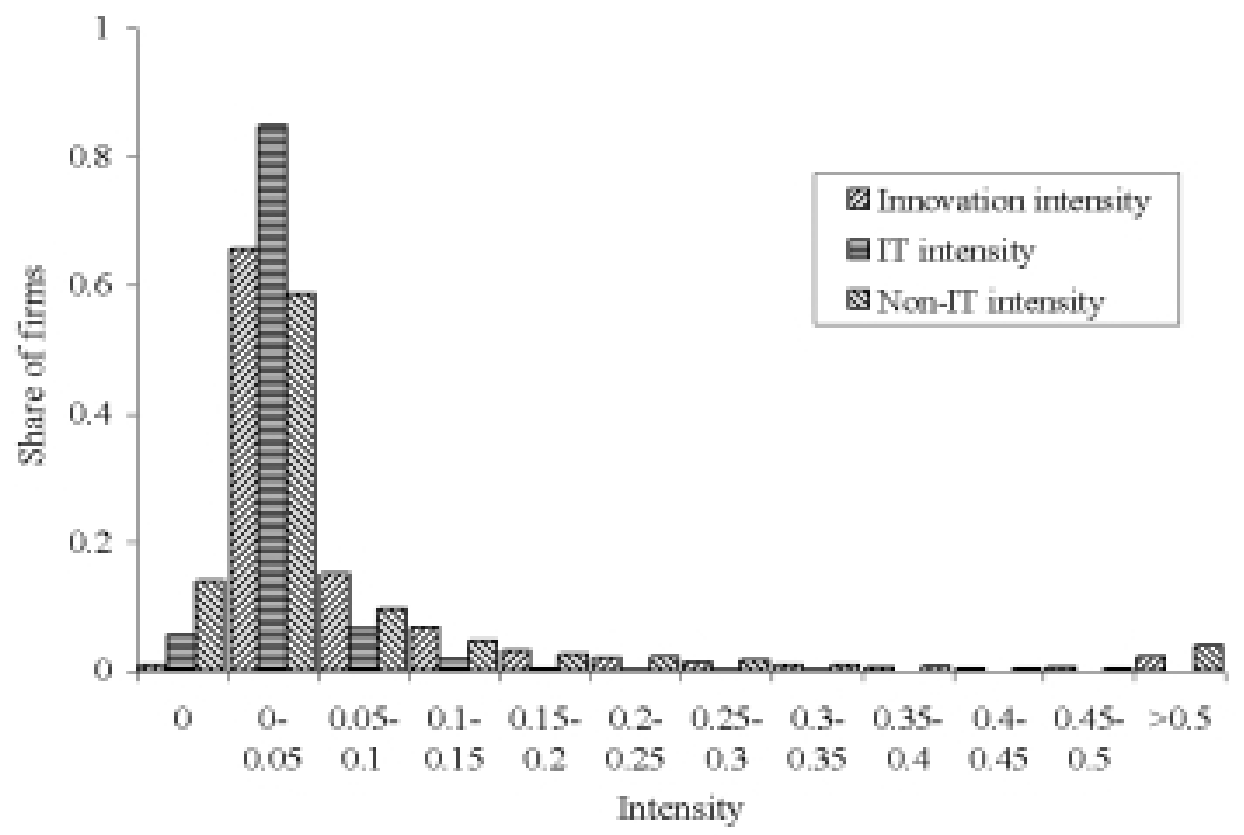

Figure 2 displays the share of firms in several categories of innovation, IT investments and non-IT investments divided by turnover (the innovation, IT and non-IT intensities). More than $60 \%$ of the firms have an innovation intensity between 0 and 0.05 , for example. Only few firms have innovation and non-IT values above 0.5 . 
Figure 3: Nonlinear effects of innovation, IT and non-IT intensities

West Germany
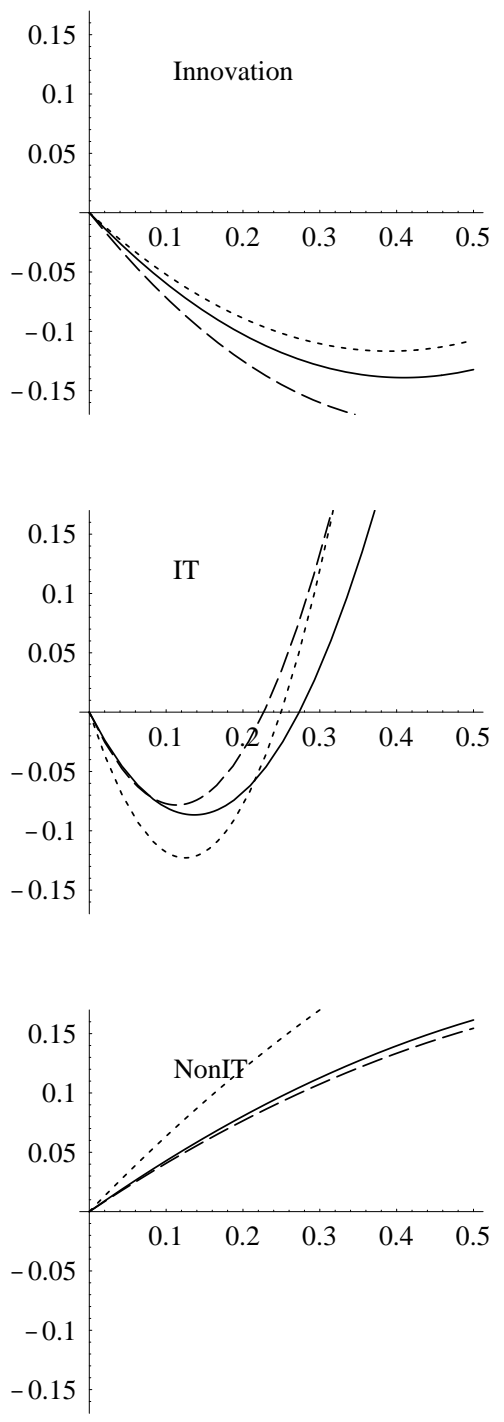

East Germany
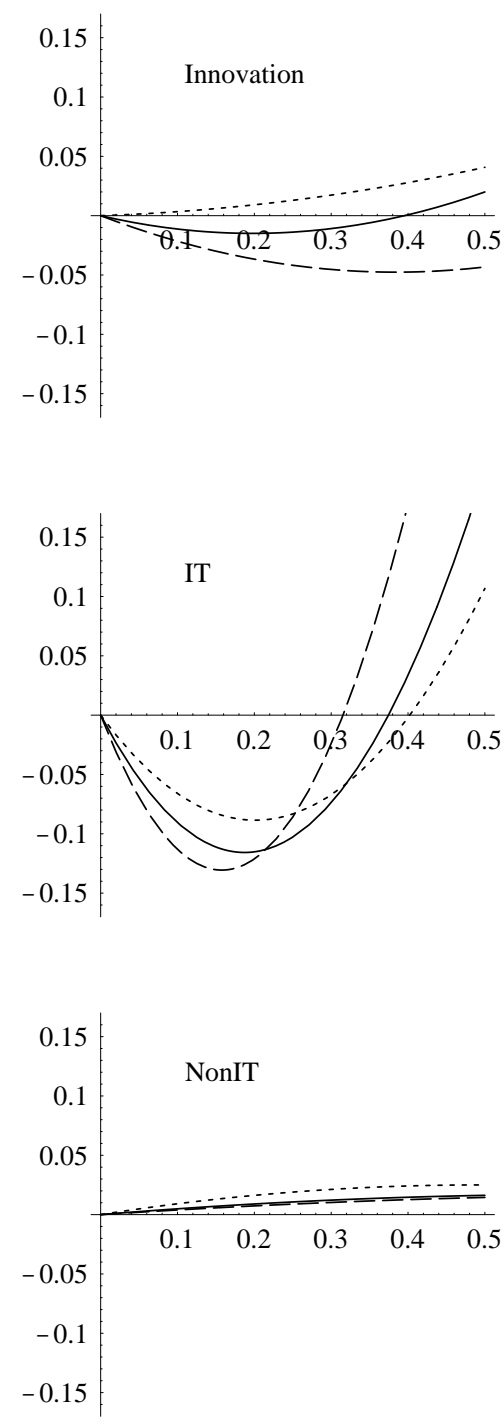

CLAD - - - - SCLS - Tobit --

The effects displayed here have a straightforward interpretation. Ceteris paribus a West German firm with an innovation intensity of 0.1 can be expected to have a medium skilled share that is 5 percentage points lower than the medium skilled share of a firm without innovation expenditures. Since the investment and innovation intensities are rarely above $20 \%$ (see Figure 2), the directions of the effects are unambiguous for relevant values but cannot be interpreted for larger values. 
Figure 4: Confidence intervals around the nonlinear effects of innovation, IT and non-IT intensities for the three estimators

West Germany
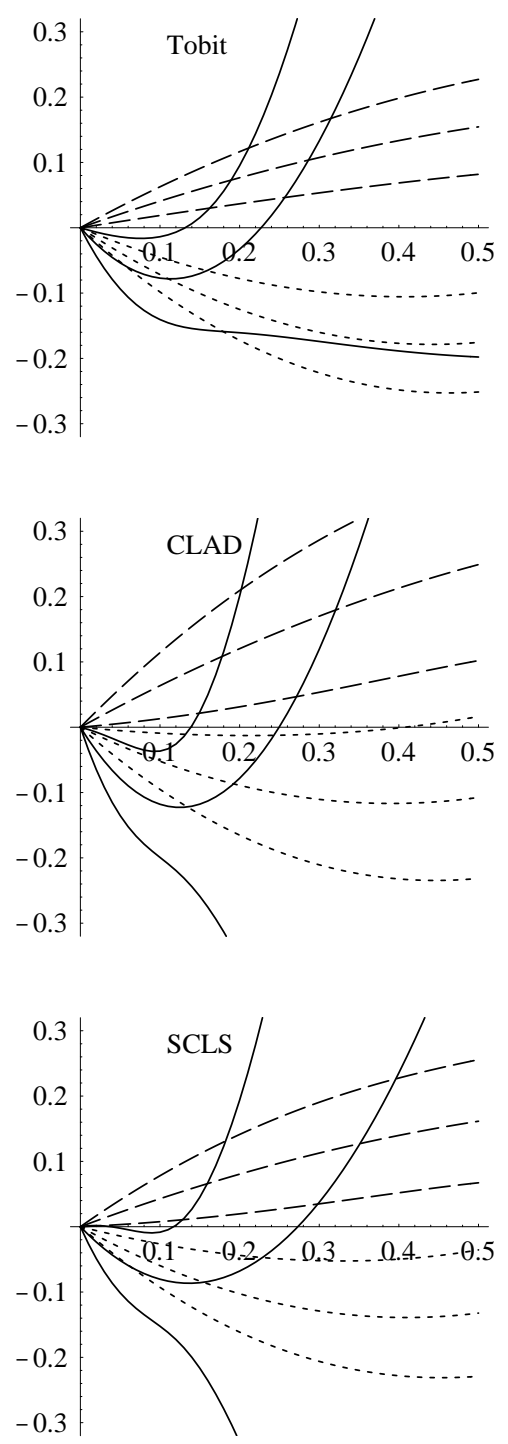

Innovation - - - - IT
East Germany
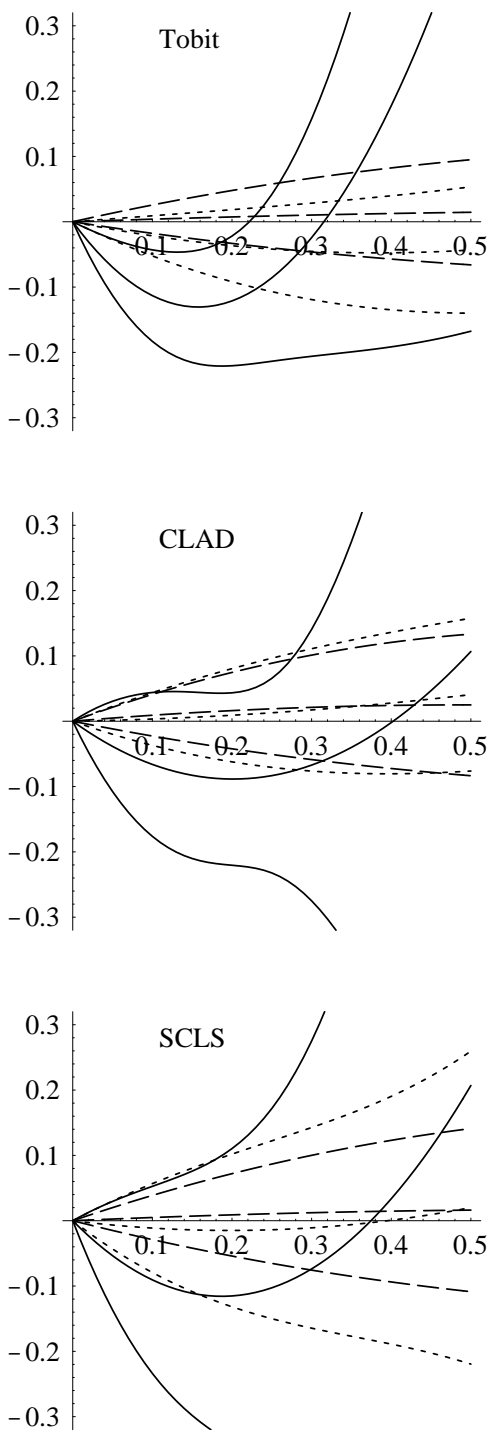

NonIT --

The 95\% confidence intervals for the Tobit, CLAD and SCLS estimations were calculated from the variances and covariances obtained from the bootstrap results. 
Table 3: Descriptive statistics: Means of variables before and after selection

\begin{tabular}{|l|r|r|r|r|}
\hline & \multicolumn{2}{|c|}{ West } & \multicolumn{2}{c|}{ East } \\
& $\begin{array}{l}\text { Before } \\
\text { selec- } \\
\text { tion }\end{array}$ & $\begin{array}{l}\text { After } \\
\text { selec- } \\
\text { tion }\end{array}$ & $\begin{array}{l}\text { Before } \\
\text { selec- } \\
\text { tion }\end{array}$ & $\begin{array}{l}\text { After } \\
\text { selec- } \\
\text { tion }\end{array}$ \\
\hline Share of medium skilled employees & 45.9 & 44.3 & 46.4 & 43.4 \\
Innovation intensity & 6.3 & 6.1 & 9.1 & 8.2 \\
IT intensity & 2.0 & 1.6 & 2.0 & 2.1 \\
Non-IT intensity & 7.2 & 5.6 & 16.8 & 12.7 \\
Share employees in R\&D departments & 3.3 & 3.7 & 4.6 & 5.6 \\
Own R\&D projects & 28.5 & 30.7 & 23.4 & 25.5 \\
Firms with 5-10 employees & 11.3 & 10.6 & 13.7 & 13.4 \\
Firms with 10-49 employees & 33.4 & 36.4 & 36.8 & 40.4 \\
Firms with 50-249 employees & 29.7 & 30.8 & 32.0 & 32.1 \\
Firms with more than 250 employees & 25.6 & 22.2 & 17.5 & 14.2 \\
Sector 1: Wholesale trade & 12.6 & 13.5 & 9.7 & 8.8 \\
Sector 2: Retail trade & 10.0 & 10.7 & 11.0 & 12.4 \\
Sector 3: Transport & 13.2 & 12.7 & 14.5 & 12.0 \\
Sector 4: Banking and insurance & 19.8 & 15.7 & 13.0 & 10.3 \\
Sector 5: Real Estate and renting & 4.7 & 4.2 & 7.6 & 6.2 \\
Sector 6: Electronic data processing & 10.3 & 11.5 & 6.3 & 6.1 \\
Sector 7: Technical services & 6.5 & 7.7 & 18.1 & 23.5 \\
Sector 8: Business services & 18.6 & 19.7 & 14.7 & 15.2 \\
Sector 9: Social and personal services & 4.4 & 4.5 & 5.0 & 5.5 \\
\hline Number of observations & 2661 & 1292 & 1407 & 741 \\
\hline
\end{tabular}

Remarks: Means before selection concern firms with five or more employees who stated to have innovated or to have started an unfinished or unsuccessful innovation project. We dropped firms with missing values on at least one of the variables above. 48 exclusions were made for plausibility reasons. Those are observations with an innovation intensity greater than one, with IT investments greater than total investments and with a non-IT intensity greater than 2 .

Source: Mannheim Innovation Panel for Services, Waves 1995, 1997, own calculations. 
Table 4: Descriptive statistics: Means by sectors (in \%, 1994-1996)

\begin{tabular}{|c|c|c|c|c|c|c|}
\hline & $\begin{array}{l}\text { Share } \\
\text { medium } \\
\text { skilled } \\
\text { em- } \\
\text { ployees }\end{array}$ & $\begin{array}{l}\text { Inno- } \\
\text { vation } \\
\text { inten- } \\
\text { sity }\end{array}$ & $\begin{array}{l}\text { IT in- } \\
\text { tensity }\end{array}$ & $\begin{array}{l}\text { Non-IT } \\
\text { inten- } \\
\text { sity }\end{array}$ & $\begin{array}{l}\text { Share } \\
\text { em- } \\
\text { ployees } \\
\text { in R\&D } \\
\text { depart- } \\
\text { ments }\end{array}$ & $\begin{array}{l}\text { Own } \\
\text { R\&D } \\
\text { projects } \\
\text { (yes/no) }\end{array}$ \\
\hline Wholesale trade & 50.6 & 3.1 & 0.8 & 3.3 & 3.2 & 29.3 \\
\hline Retail trade & 58.9 & 3.9 & 0.9 & 5.0 & 1.7 & 18.7 \\
\hline Transport & 51.1 & 9.8 & 0.9 & 19.7 & 0.5 & 24.1 \\
\hline Banking and insurance & 54.6 & 2.6 & 1.3 & 2.0 & 0.6 & 14.7 \\
\hline Real Estate and renting & 53.1 & 3.6 & 1.5 & 35.3 & 0.9 & 14.0 \\
\hline Electronic data processing & 27.1 & 14.0 & 4.0 & 2.9 & 13.5 & 55.4 \\
\hline Technical services & 28.6 & 12.1 & 3.5 & 5.3 & 13.2 & 48.4 \\
\hline Business services & 37.2 & 4.9 & 1.7 & 3.9 & 2.5 & 25.3 \\
\hline Social and personal services & 37.2 & 9.5 & 1.2 & 21.2 & 1.6 & 24.2 \\
\hline
\end{tabular}

Remarks: The means were calculated for the estimation sample.

Source: Mannheim Innovation Panel for Services, Waves 1995, 1997, own calculations. 